\title{
Does a third arterial conduit to the right coronary circulation improve survival?
}

\author{
Suvitesh Luthra, FRCS(CTh), ${ }^{a}$ Miguel M. Leiva-Juárez, MD, ${ }^{b}$ Maciej Matuszewski, FRCS(CTh), \\ Ian S. Morgan, FRCS(CTh), ${ }^{c}$ and John S. Billing, FRCS(CTh ${ }^{c}$
}

\section{ABSTRACT}

Background: The long-term benefits of a third arterial conduit to the right circulation in triple-vessel disease remain debatable. This retrospective, single-center, propensity-matched study investigates the impact of a third arterial conduit to the right circulation on early and intermediate survival after coronary artery bypass grafting.

Methods: Data were retrospectively collected from 2004 to 2014 for all surgical revascularizations for triple-vessel disease with at least 2 arterial conduits to the left circulation and a third arterial or venous conduit to the right circulation. A total of 167 pairs were propensity matched to arterial versus venous third conduit to right circulation. Hazard functions were obtained with Cox multivariate regression and Kaplan-Meier survival curves were compared between the matched cohorts.

Results: Extracardiac arteriopathy, logistic euroSCORE, and left main stem disease were significant predictors of adverse survival. A third arterial conduit to the right circulation was not a significant predictor of improved survival in multivariate analysis (HR, 0.72; 95\% CI, 0.34-1.55; $P=.411) .30$-day mortality was $0.6 \%$ in both groups. There was no significant difference in early or intermediate survival in the propensity-matched groups (venous vs arterial, $99.2 \%$ vs $99.2 \% ; P=1.000$ at 1 year; $85.2 \%$ vs $88.8 \% ; P=.248$ at 5 years and $69.2 \%$ vs $88.8 \% ; P=.297$ at 7 years)

Conclusions: The use of a third arterial versus a venous conduit to the right circulation does not improve early or intermediate survival up to 7 years in triple-vessel coronary artery disease in this study. Longer follow-up and larger cohorts may be needed for differences to emerge. (J Thorac Cardiovasc Surg 2018;155:855-60)

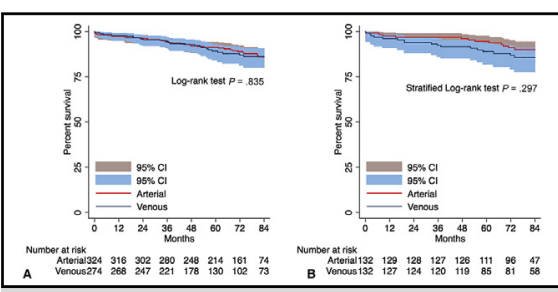

Overall survival by addition of a third arterial or venous conduit to the right coronary circulation.

\section{Central Message}

The use of a third arterial versus a venous conduit to the right circulation does not improve early or intermediate survival up to 7 years in triple-vessel coronary artery disease.

\section{Perspective}

The use of an arterial conduit has traditionally been associated with better patency rates and better clinical outcomes during revascularization of left coronary territories; however, the clinical usefulness to the right circulation remains debatable. In this study, we compare early and intermediate survival by the type of conduit to the right circulation during triplevessel disease revascularization.

See Editorial Commentaries pages 861 and 863.

See Editorial page 853
Arterial conduits have better patency rates and have been associated with a survival benefit in surgical revascularization. The choice of additional conduit to the right coronary circulation has been a radial artery (RA), right internal

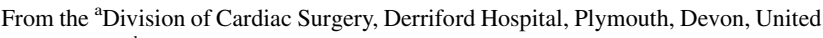
Kingdom; ' Department of Pulmonary Medicine, MD Anderson Cancer Center, Houston, Tex; and ${ }^{\mathrm{c}}$ Department of Cardiothoracic Surgery, New Cross Hospital, Wolverhampton, West Midlands, United Kingdom.

Received for publication April 17, 2017; revisions received Aug 12, 2017; accepted for publication Sept 7, 2017; available ahead of print Dec 14, 2017

Address for reprints: Suvitesh Luthra, FRCS(CTh), Level 9, Terence Lewis Bldg, Derriford Hospital, Plymouth PL6 8DH, Devon, United Kingdom (E-mail: drs100@gmail.com).

$0022-5223 / \$ 36.00$

Copyright (C) 2017 by The American Association for Thoracic Surgery

https://doi.org/10.1016/j.jtcvs.2017.09.163
}

thoracic artery (ITA) or rarely a right gastroepiploic artery. Patency rates for right-sided grafts have generally been lower than those for left-sided grafts both for arterial and for venous grafts. ${ }^{1,2}$ There has been a call for additional arterial grafts to improve survival. ${ }^{3,4}$ Additional arterial grafting has not been shown to provide survival benefits from revascularization of the right coronary territory.

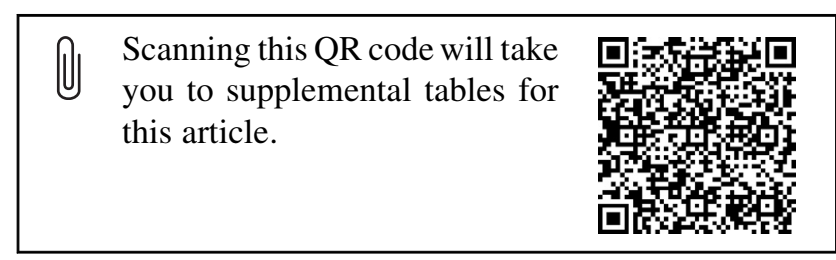




$$
\begin{aligned}
& \text { Abbreviations and Acronyms } \\
& \begin{aligned}
\text { CABG } & =\text { Coronary artery bypass grafting } \\
\text { CI } & =\text { Confidence interval } \\
\text { HR } & =\text { Hazard ratio } \\
\text { ITA } & =\text { Internal thoracic artery } \\
\text { LAD } & =\text { Left anterior descending artery } \\
\text { LVEF } & =\text { Left ventricular ejection fraction } \\
\text { MI } & =\text { Myocardial infarction } \\
\text { RA } & =\text { Radial artery } \\
\text { RIMA } & =\text { Right internal mammary artery } \\
\text { SVG } & =\text { Saphenous vein graft }
\end{aligned}
\end{aligned}
$$

The aim of this study was to assess the early and intermediate survival benefit of a third arterial graft to the right coronary circulation as opposed to venous grafts.

\section{METHODS}

Data for isolated coronary artery bypass grafting (CABG) were retrospectively collected from 2004 to 2014 from the New Cross Hospital database (PATS [Dentrite Clinical Systems Ltd, Henley-on-Thames, United Kingdom]). We included all patients with triple-vessel disease with arterial grafts to left anterior descending artery (LAD) and circumflex circulation and a third venous or arterial graft (ITA or RA) to the right coronary circulation (right coronary artery or posterior descending or posterior ventricular artery) (Figure 1). Patients with a venous graft to the circumflex system, single-vessel/double-vessel disease and those with other concomitant procedures were excluded. The use of radial arteries to the right or left circulation was restricted to vessels with severe lesions. The hospital database is reviewed, audited, and validated monthly by audit officers and linked to a national UK database. Consent for individual use of data was waived because of the nature of the study and previous approval for use of such data at the time of operative consent. Long-term survival statistics were collected from the NICOR (National Institute of Cardiac Outcomes Research, United Kingdom) database (release June 2015).

\section{Data Analysis}

Baseline demographic characteristics for CABG were stratified for arterial versus venous third conduit to the right coronary circulation after at least 2 other arterial grafts to the left circulation. Distributions from each variable were visually inspected and normality was tested by a Shapiro-Wilcoxon $W$ test. Continuous variables were compared using a Mann-Whitney test and categorical variables by $\chi^{2}$ test. $P \leq .05$ was considered significant.

\section{Propensity Score Matching}

Propensity matching was used to balance the covariates in the nonrandomized, observational data. The following covariates were included in the propensity match: age, logistic euroSCORE (European System for Cardiac Operative Risk Evaluation), body mass index, gender, hypercholesterolemia, pulmonary disease, neurologic disease, renal disease, hypertension, left main stem disease, diabetes, left ventricular ejection fraction (LVEF), New York Heart Association classification, previous percutaneous coronary intervention, and previous myocardial infarction. The definitions used for these risk factors were as previously described for calculation of euroSCORE by Roques et al. ${ }^{5,6}$

The propensity score for use of a third arterial conduit to the right coronary circulation was estimated by logistic regression. Variables included in the propensity match model were chosen by clinical relevance

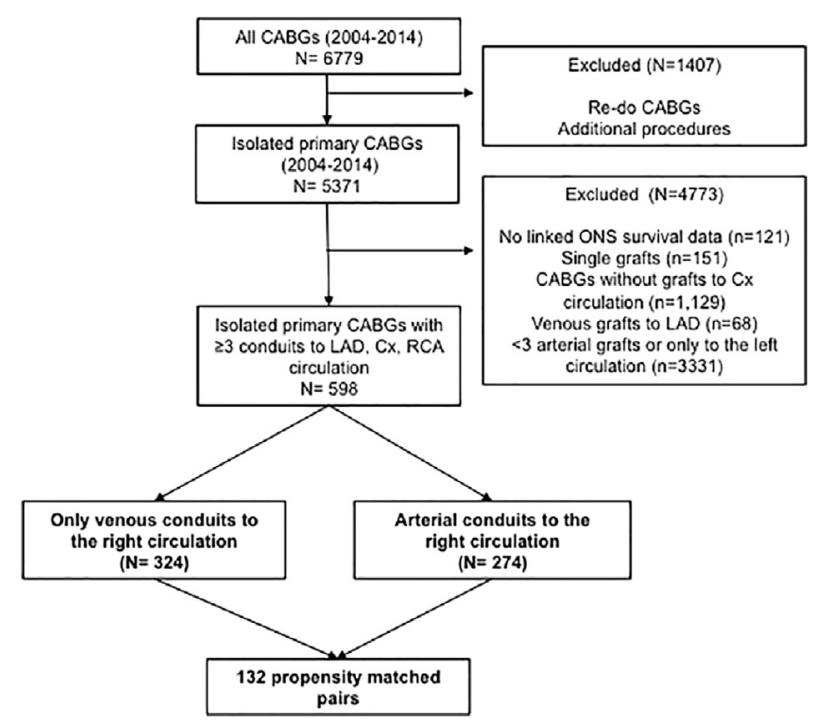

FIGURE 1. Data flowchart for patients included in the study. $C A B G$, Coronary artery bypass grafting; ONS, Office for National Statistics; $C x$, circumflex; $L A D$, left anterior descending artery; $R C A$, right coronary artery.

and included in the model by an iterative process until almost all variables were successfully balanced. The treated observations were posteriorly matched in a 1:1 ratio using the nearest-neighbor method with a caliper width of 0.2 of the standard deviation of the propensity score logit. Means, standard deviations, and proportions of baseline demographic characteristics were compared to ensure appropriate balance among groups and statistical significance was tested by comparing standardized bias among each of the variables; those with a standardized bias within $\pm 10 \%$ were considered appropriately balanced (Figure 2). Despite sequential modeling, extracardiac arteriopathy and LVEF $<30 \%$ remained unbalanced so these variables were incorporated in the multivariable analysis as described in the next section.

\section{Hazard Functions and Survival Analysis}

Kaplan-Meier survival curves were plotted for the matched and unmatched data and the equality of survivor functions was tested using a log-rank test. To analyze the association between risk factors and survival among the propensity-matched cohorts, each covariate was tested for prediction using a Cox proportional hazards model or a log-rank test, respectively. All covariates with a $P \leq .2$ as well as those unbalanced were included in the multivariate model, and the proportional hazard assumption was tested using Schoenfeld residuals. Hazard ratios (HRs) were calculated for each variable. Overall survival was compared using a log-rank test; this test was stratified by the pair identification in the propensity-matched cohort.

\section{RESULTS}

A total of 598 patients with triple-vessel disease were included in the study (274 venous; 324 arterial). All patients had an ITA to the LAD and at least 1 arterial graft (RA or ITA) to the circumflex circulation. Median follow-up was 85 (interquartile range, 68-105) months versus 51 (interquartile range, 35.5-87) months $(P=.024)$ for venous and arterial grafts, respectively. The baseline demographics and operative characteristics are shown in Table 1. 


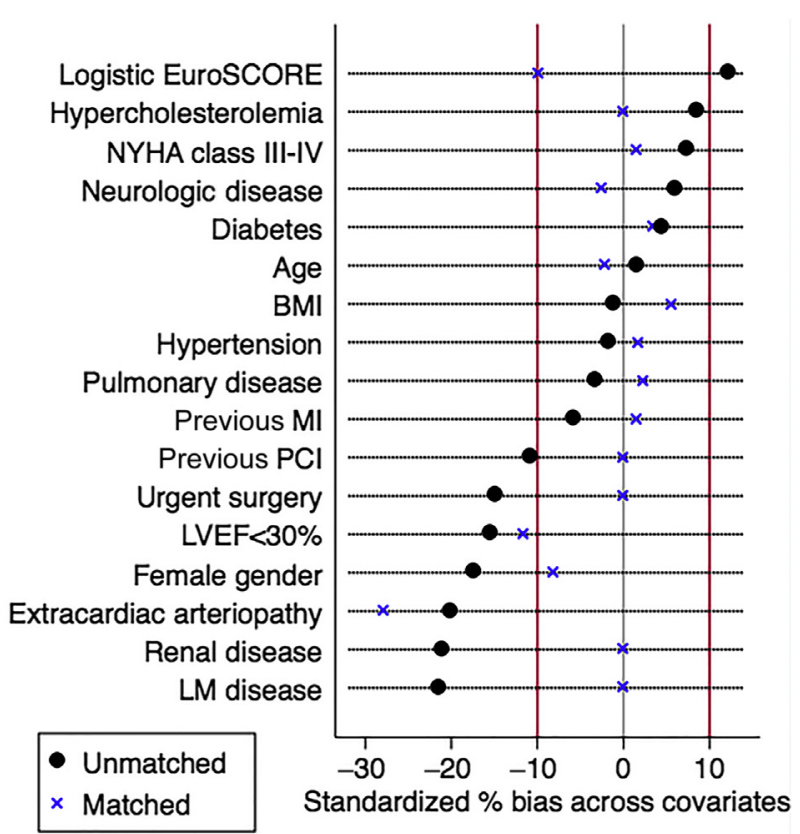

FIGURE 2. Percent bias plot from the propensity-matching model. NYHA, New York Heart Association; BMI, body mass index; MI, myocardial infarction; $P C I$, percutaneous coronary intervention; $L V E F$, left ventricular ejection fraction; $L M$, left main.

A total of 167 pairs were propensity matched to the venous or arterial (third conduit) to right coronary circulation. Most of the arterial grafts to the right circulation were RAs (Tables E1 and E2). Of those patients who had bilateral internal mammary arteries to the left circulation, 60 had single radial conduits to the right circulation. Cox proportional hazards regression analysis in the propensity-matched cohorts identified extracardiac arteriopathy, logistic euroSCORE, and left main stem disease as significant predictors of adverse survival (Table 2). A third arterial graft to the right coronary circulation as opposed to a venous conduit was not a significant predictor of improved early or late survival (univariable: HR, $0.65 ; 95 \%$ confidence interval [CI], $0.31-1.35 ; P=.246$ ) (multivariable: $\mathrm{HR}, 0.72 ; 95 \% \mathrm{CI}$, $0.34-1.55 ; P=.411)$.

\section{Early and Midterm Survival (up to 5 Years)}

The 30-day mortality was comparable in the 2 groups: unmatched, 99.6\% (venous) versus $98.8 \%$ (arterial), $P=.225$ and $99.2 \%(P=1.000)$ for both propensitymatched groups. The survival did not differ significantly in the unmatched and propensity-matched groups at 1,2, 3 , and 5 years (Figure 3 and Table E3).

\section{Intermediate Survival (up to 7 Years)}

There was no significant difference in survival in unmatched $(69.01 \%$ vs $83.48 \% ; P=.84)$ or matched cohorts $(69.2 \%$ vs $88.8 \% ; P=.297)$ at 7 years.
There was an accelerated decline in survival in the venous group both for unmatched and propensity-matched cohorts after 84 months. The differences in survival remained statistically insignificant up to 8 years. However, the numbers at risk were sufficiently low.

\section{Right Internal Mammary Artery Versus RAs}

Right internal mammary artery (RIMA) was used in $8.3 \%$ of the arterial grafts to the right circulation. There was no difference in survival between RIMA and RAs for the right circulation (overall log-rank, $P=.859$ ), although the numbers were small.

\section{DISCUSSION}

The benefits of total arterial revascularization especially for arterial grafts to the right coronary circulation remain debatable. There is a consensus that left internal mammary artery to LAD artery offers a long-term survival benefit and addition of another arterial graft to the left circulation improves survival. $^{7-9}$ This evidence in recent studies has extended to the use of RAs as second-best conduits after ITAs.

Grau et al. recently failed to show any statistical difference in survival up to 14 years in comparison of RA and saphenous vein grafts (SVG) to right coronary circulation with bilateral ITA to the left circulation. ${ }^{10}$ At least 2 other recent propensity-matched studies have found similar results with the use of radial arteries as the third arterial conduit to right coronary circulation. ${ }^{11}$

A common strategy for proponents of arterial revascularization is to use the 2 ITAs for the left circulation and an RA for the right coronary circulation. The use of the RA and ITA to the right coronary circulation is limited to good caliber vessels in right dominant systems and significant stenosis $>80 \%$. In situ right ITA conduit may be limited by its length for grafting beyond the crux. These constraints with length can be overcome with skeletonization and use as a free graft with proximal aortic anastomosis or as a Y-graft from any of the left-sided grafts. The radial arteries have superb handling and length. These are easier to use as free or Y-grafts, with or without proximal anastomosis on the ascending aorta. For moderate right-sided lesions, the conventional wisdom has been to prefer venous conduits. This preference is because of stringing commonly seen in arterial conduits as a result of native competitive flow in moderate severity lesions.

It is reasonable to assume that the benefits of a third arterial graft may be caused by superior graft patency. Reported arterial graft patencies have been superior to SVGs both for right-sided and left-sided coronary circulations in randomized trials with protocol angiograms. $^{12,13}$ However, observational studies have reported better SVG patencies in early and midterm results compared with arterial grafts. ${ }^{14-16}$ In a review 
TABLE 1. Demographic characteristics

\begin{tabular}{|c|c|c|c|c|c|c|}
\hline & $\frac{\text { Venous }(n=274)}{\text { Median }(I Q R)}$ & $\frac{\text { Arterial }(n=324)}{\text { Median }(I Q R)}$ & $P$ value & $\frac{\text { Venous }(n=132)}{\text { Median }(I Q R)}$ & $\frac{\text { Arterial }(n=132)}{\text { Median }(\mathrm{IQR})}$ & $P$ value \\
\hline Age (y) & $67(59-73)$ & $67(59-73)$ & .994 & $67(60-72)$ & $65(58-73.5)$ & .902 \\
\hline Crossclamp time (min) & $51.5(42-64)$ & $37(25-59)$ & $<.001$ & $84(69-106)$ & $47(14-85)$ & $<.001$ \\
\hline Follow-up (mo) & $85(68-105)$ & $51(35.5-87)$ & .024 & $83.4(56.6-89.7)$ & $79(70.9-89.4)$ & $<.001$ \\
\hline Bypass time (min) & $58.3(40.6-86.9)$ & $71.7(50-83.5)$ & $<.001$ & $50(42-63)$ & $35(0-57)$ & $<.001$ \\
\hline EuroSCORE & $2(1-4)$ & $3(2-5)$ & .001 & $2(1-4)$ & $2(1-3.5)$ & .235 \\
\hline Logistic EuroSCORE & $1.6(0.94-3.2)$ & $2.2(1.4-3.7)$ & .003 & $1.69(1.07-2.98)$ & $1.66(1.11-2.54)$ & .376 \\
\hline \multirow[t]{2}{*}{ BMI } & $28.5(25.8-31.3)$ & $28.4(25.7-30.7)$ & .632 & $28.87(2.7-31.5)$ & $28.68(26.4-31.6)$ & .626 \\
\hline & n $(\%)$ & n $(\%)$ & & & & \\
\hline \multicolumn{7}{|l|}{ Gender } \\
\hline $\begin{array}{l}\text { Female } \\
\text { Male }\end{array}$ & $\begin{array}{r}54(19.71) \\
220(80.29)\end{array}$ & $\begin{array}{r}43(13.27) \\
281(86.73)\end{array}$ & .033 & $\begin{array}{r}26(19.70) \\
106(80.30)\end{array}$ & $\begin{array}{l}22(16.67) \\
110(83.33)\end{array}$ & .608 \\
\hline Sinus rhythm & $66(24.09)$ & $93(28.70)$ & .203 & $98(74.24)$ & $101(76.52)$ & .784 \\
\hline $\begin{array}{l}\text { Operative urgency } \\
\text { Elective } \\
\text { Nonelective }\end{array}$ & $\begin{array}{r}179(65.33) \\
95(34.67)\end{array}$ & $\begin{array}{l}221(68.21) \\
103(31.79)\end{array}$ & .456 & $\begin{array}{r}106(80.30) \\
26(19.70)\end{array}$ & $\begin{array}{r}114(86.36) \\
18(13.64)\end{array}$ & .229 \\
\hline \multicolumn{6}{|c|}{ Extent of coronary vessel disease } & 1.000 \\
\hline Left main disease & $84(30.66)$ & $69(21.30)$ & .009 & $40(30.30)$ & $40(30.30)$ & 1.000 \\
\hline Pulmonary disease & 35 (12.77) & $38(11.73)$ & .697 & $20(15.15)$ & $21(15.91)$ & 1.000 \\
\hline Neurologic disease & $23(8.39)$ & $33(10.19)$ & .462 & $7(5.30)$ & $6(4.55)$ & 1.000 \\
\hline Renal disease & $66(24.09)$ & $51(15.74)$ & .010 & $0(0.00)$ & $0(0.00)$ & 1.000 \\
\hline Hypertension & $194(70.80)$ & $227(70.06)$ & .843 & $89(67.42)$ & $90(68.18)$ & 1.000 \\
\hline Diabetes & $69(25.18)$ & $88(27.16)$ & .584 & 29 (21.97) & $31(23.48)$ & 1.000 \\
\hline LVEF $<30 \%$ & $15(5.47)$ & $8(2.47)$ & .057 & $8(6.06)$ & $5(3.79)$ & .549 \\
\hline $\begin{array}{l}\text { CCS class of angina } \\
\text { I-II } \\
\text { III-IV }\end{array}$ & $\begin{array}{l}129(47.08) \\
145(52.92)\end{array}$ & $\begin{array}{l}135(41.67) \\
189(58.33)\end{array}$ & .184 & $\begin{array}{l}89(67.42) \\
43(32.58)\end{array}$ & $\begin{array}{l}90(68.18) \\
42(31.82)\end{array}$ & 1.000 \\
\hline $\begin{array}{l}\text { NYHA status } \\
\text { I-II } \\
\text { III-IV }\end{array}$ & $\begin{array}{l}137(50.00) \\
137(50.00)\end{array}$ & $\begin{array}{l}150(46.30) \\
174(53.70)\end{array}$ & .366 & $\begin{array}{l}74(56.06) \\
58(43.94)\end{array}$ & $\begin{array}{l}73(55.30) \\
59(44.70)\end{array}$ & 1.000 \\
\hline Previous PCI & $45(16.42)$ & $41(12.65)$ & .191 & $18(13.64)$ & $18(13.64)$ & 1.000 \\
\hline Extracardiac arteriopathy & $59(21.53)$ & $45(13.89)$ & .014 & $34(25.76)$ & $20(15.15)$ & .016 \\
\hline Previous MI & $154(56.20)$ & $173(53.40)$ & .492 & $79(59.85)$ & $80(60.61)$ & 1.000 \\
\hline
\end{tabular}

$I Q R$, Interquartile range; $B M I$, body mass index; $L V E F$, left ventricular ejection fraction; CCS, Canadian Cardiovascular Society; NYHA, New York Heart Association; $P C I$, percutaneous coronary intervention; $M I$, myocardial infarction.

comparing SVG with right ITA, Mukherjee et al. ${ }^{17}$ found that SVGs had superior graft functionality (odds ratio, $6.1 ; 95 \%$ CI, 2.4-15) compared with the other conduits. Graft function was negatively influenced by the minimum lumen diameter (odds ratio, 0.11; CI, 0.05-0.25). In the RAPCO (Radial Artery Patency and Clinical Outcomes) study, patency of free arterial conduits and SVG was $89.1 \%$ versus $82.4 \%$, respectively, which did not differ significantly $(P=.09)$ at 5 years. ${ }^{18}$ The trial failed to show any significant differences in angiographic or clinical outcomes between arterial and venous grafts even at 8 years.

The physiology of the right coronary circulation is also probably different from the left. It has a smaller runoff even in right dominant circulations. The size of the distal vessels is likely to be smaller than on the left. It predominantly supplies a low-pressure chamber of the heart with lesser muscle mass compared with the left. Late graft failure may therefore be more forgiving for the right circulation compared with the left. Likewise, the benefits of 
TABLE 2. Univariate and multivariate Cox regression analysis

\begin{tabular}{|c|c|c|c|c|c|c|}
\hline & \multicolumn{3}{|c|}{ Univariable } & \multicolumn{3}{|c|}{ Multivariable } \\
\hline & $\overline{\text { HR }}$ & 95 $\%$ Confidence interval & $P$ value & $\overline{\text { HR }}$ & 95 $\%$ Confidence Interval & $P$ value \\
\hline Artery to right circulation & 0.65 & $0.31-1.35$ & .246 & 0.72 & $0.34-1.55$ & .411 \\
\hline Age & 1.02 & $0.98-1.06$ & .383 & & & \\
\hline Logistic euroSCORE & 1.23 & $1.14-1.33$ & $<.001$ & 1.24 & $1.10-1.39$ & $<.001$ \\
\hline BMI & 1.01 & $0.93-1.10$ & .734 & & & \\
\hline Extracardiac arteriopathy & 3.97 & $1.92-8.23$ & $<.001$ & 1.95 & $0.92-4.14$ & .083 \\
\hline Female gender & 2.10 & $0.96-4.61$ & .064 & 2.09 & $0.95-4.56$ & .066 \\
\hline Pulmonary disease & 0.61 & $0.18-2.02$ & .418 & & & \\
\hline Neurologic disease & 0.71 & $0.10-5.24$ & .74 & & & \\
\hline Hypertension & 0.64 & $0.30-1.33$ & .23 & & & \\
\hline LM disease & 0.95 & $0.43-2.09$ & .902 & & & \\
\hline Diabetes & 0.69 & $0.26-1.81$ & .45 & & & \\
\hline LVEF $<30 \%$ & 2.27 & $0.69-7.50$ & .179 & 0.26 & $0.05-1.39$ & .115 \\
\hline NYHA III-IV & 0.92 & $0.44-1.92$ & .821 & & & \\
\hline Previous PCI & 1.56 & $0.63-3.82$ & .334 & & & \\
\hline Previous MI & 1.22 & $0.57-2.62$ & .614 & & & \\
\hline Date of operation & 0.99 & $0.99-1.00$ & .109 & 1.00 & $0.99-1.00$ & .234 \\
\hline
\end{tabular}

$H R$, Hazard ratio; $B M I$, body mass index; $L M$, left main; $L V E F$, left ventricular ejection fraction; $N Y H A$, New York Heart Association; $P C I$, percutaneous coronary intervention; $M I$, myocardial infarction.

superior patency might not affect clinical outcomes or longterm survival.

There are likely explanations why our study might have failed to show any benefit from an additional arterial graft to the right coronary circulation. The mean age in both groups in this study was around 66 years. The survival benefits of multiple arterial grafting may not be fully realized before 10-15 years. Studies that have shown survival benefits with multiple arterial grafting had long follow-ups. ${ }^{19-22}$ The recent results of the Arterial

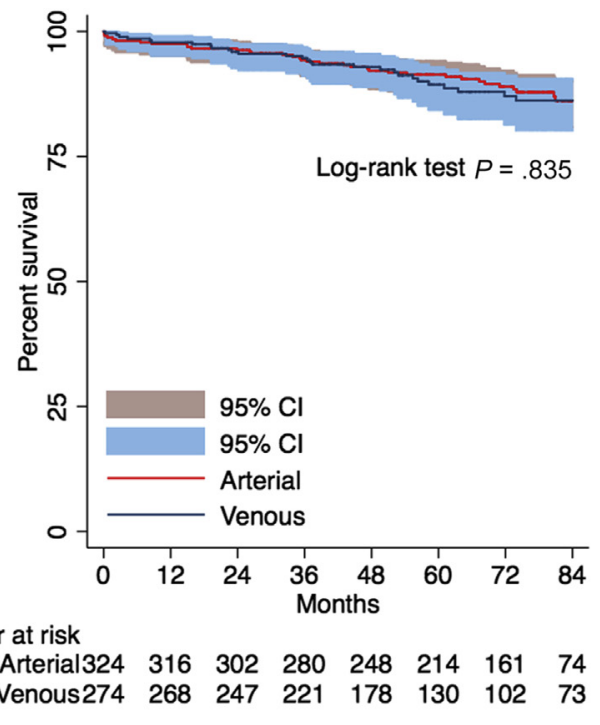

Revascularization Trial have similarly failed to show benefit even from a second ITA at 5 years. Our follow-up of 10 years may not have been long enough to realize these differences. The survival curves for the venous group digress sharply downward after 7 years in our study. This digression may be caused by late vein graft loss and is likely to have been significant with a longer follow-up if numbers at risk remain significant.

Although propensity matched, this is a retrospective analysis, which could not have corrected for all the inherent

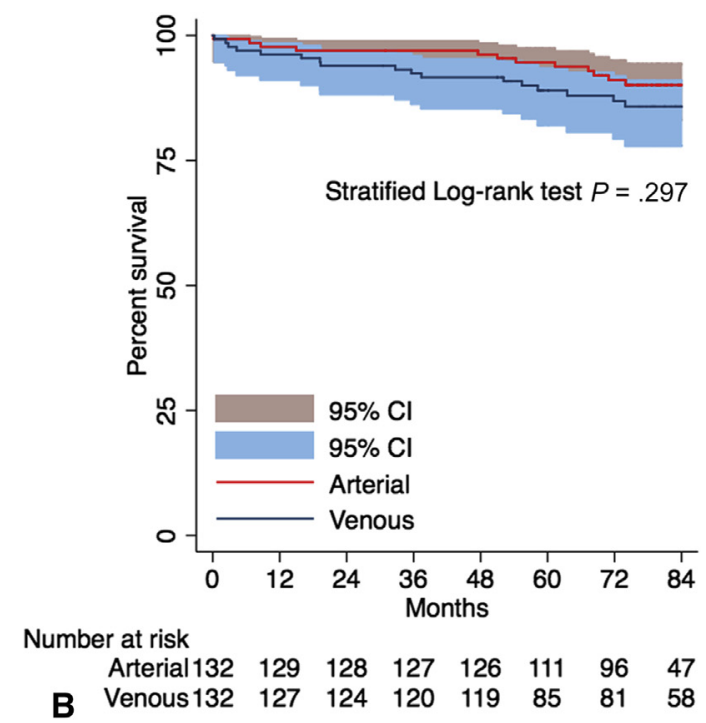

FIGURE 3. Overall survival in unmatched (A) and propensity-matched groups (B) stratified by the type of conduit to the right coronary circulation. CI, Confidence interval. 
biases in patient selection. Propensity matching could be achieved only for $44 \%$ of the patients (264/598). This factor suggests a significant heterogeneity between groups. Small subgroup numbers and limitations of data did not allow further analysis for confounders such as surgical techniques, surgeons, and arterial grafting trends over the decade of the study.

The lesion severity for the right-sided grafts is an important correlate for graft patency, especially RAs. Angiographic graft patency was also not assessed in this study for its correlation to survival.

Age cutoff for any benefit from arterial grafts for the left circulation has been 65-70 years and even lower for those with diabetes. ${ }^{23,24}$ For multiple arterial grafting including to the right circulation, age remains controversial. The mean age in this study was 66 years and might have affected the benefits of multiple arterial grafting.

Data for secondary prevention and control of risk factors and compliance with medical therapy were not available. Low compliance could have significant bearing on graft patency rates.

\section{CONCLUSIONS}

A third arterial graft to the right coronary circulation does not improve early or intermediate survival for up to 7 years in this study. Longer follow-up and larger cohorts may be needed to show any benefits.

\section{Conflict of Interest Statement}

Authors have nothing to disclose with regard to commercial support.

The authors thank Sarah Pickford and Christopher Newman, Senior Cardiothoracic Data Audit \& Information Officers, New Cross Hospital for collation and validation of data.

\section{References}

1. Pevni D, Uretzky G, Yosef P, Yanay BG, Shapira I, Nesher N, et al. Revascularization of the right coronary artery in bilateral internal thoracic artery grafting. Ann Thorac Surg. 2005;79:564-9.

2. Shah PJ, Durairaj M, Gordon I, Fuller J, Rosalion A, Seevanayagam S, et al. Factors affecting patency of internal thoracic artery graft: clinical and angiographic study in 1434 symptomatic patients operated between 1982 and 2002. Eur J Cardiothorac Surg. 2004;26:118-24.

3. Halkos ME, Guyton RA. Coronary bypass: is it time to take the next step-the routine use of the second arterial graft? J Thorac Cardiovasc Surg. 2014;148: $1149-51$.

4. Rosengart TK. Total arterial revascularization: when will its time come? J Thorac Cardiovasc Surg. 2014;148:1244-5.

5. Roques F, Nashef SA, Michel P, Gauducheau E, de Vincentiis C, Baudet E, et al. Risk factors and outcome in European cardiac surgery: analysis of the EuroSCORE multinational database of 19030 patients. Eur J Cardiothorac Surg. 1999; 15:816-22; discussion 822-3.

6. Roques F, Michel P, Goldstone AR, Nashef SA. The logistic EuroSCORE. Eur Heart J. 2003;24:881-2.

7. Buxton BF, Ruengsakulrach P, Fuller J, Rosalion A, Reid CM, Tatoulis J. The right internal thoracic artery graft-benefits of grafting the left coronary system and native vessels with a high grade stenosis. Eur J Cardiothorac Surg. 2000;18: 255-61.

8. Kurlansky PA, Traad EA, Dorman MJ, Galbut DL, Zucker M, Ebra G. Thirty-year follow-up defines survival benefit for second internal mammary artery in propensity-matched groups. Ann Thorac Surg. 2010;90:101-8.

9. Taggart DP, D'Amico R, Altman DG. Effect of arterial revascularisation on survival: a systematic review of studies comparing bilateral and single internal mammary arteries. Lancet. 2001;358:870-5.

10. Grau JB, Kuschner CE, Johnson CK, Ferrari G, Zapolanski A, Brizzio ME, et al. The effects of using a radial artery in patients already receiving bilateral internal mammary arteries during coronary bypass grafting: 30-day outcomes and 14-year survival in a propensity-matched cohort. Eur J Cardiothorac Surg. 2016;49:203-10.

11. Benedetto U, Caputo M, Zakkar M, Bryan A, Angelini GD. Are three arteries better than two? Impact of using the radial artery in addition to bilateral internal thoracic artery grafting on long-term survival. J Thorac Cardiovasc Surg. 2016; $152: 862-9 . e 862$

12. Deb S, Cohen EA, Singh SK, Une D, Laupacis A, Fremes SE, RAPS Investigators. Radial artery and saphenous vein patency more than 5 years after coronary artery bypass surgery: results from RAPS (Radial Artery Patency Study). J Am Coll Cardiol. 2012;60:28-35.

13. Collins P, Webb CM, Chong CF, Moat NE, Investigators RAVSVPRT. Radial artery versus saphenous vein patency randomized trial: five-year angiographic follow-up. Circulation. 2008;117:2859-64.

14. Shah PJ, Bui K, Blackmore S, Gordon I, Hare DL, Fuller J, et al. Has the in situ right internal thoracic artery been overlooked? An angiographic study of the radial artery, internal thoracic arteries and saphenous vein graft patencies in symptomatic patients. Eur J Cardiothorac Surg. 2005;27:870-5.

15. Yi G, Youn YN, Song SW, Yoo KJ. Off-pump right coronary artery bypass with saphaneous vein or in-situ right internal thoracic artery. Ann Thorac Surg. 2010; $89: 717-22$.

16. Glineur D, D'hoore W, de Kerchove L, Noirhomme P, Price J, Hanet C, et al. Angiographic predictors of 3-year patency of bypass grafts implanted on the right coronary artery system: a prospective randomized comparison of gastroepiploic artery, saphenous vein, and right internal thoracic artery grafts. J Thorac Cardiovasc Surg. 2011;142:980-8.

17. Mukherjee D, Cheriyan J, Kourliouros A, Athanasiou T. Does the right internal thoracic artery or saphenous vein graft offer superior revascularization of the right coronary artery? Interact Cardiovasc Thorac Surg. 2012;15:244-7.

18. Hayward PA, Buxton BF. Mid-term results of the Radial Artery Patency and Clinical Outcomes randomized trial. Ann Cardiothorac Surg. 2013;2:458-66.

19. Locker C, Schaff HV, Dearani JA, Joyce LD, Park SJ, Burkhart HM, et al. Multiple arterial grafts improve late survival of patients undergoing coronary artery bypass graft surgery: analysis of 8622 patients with multivessel disease. Circulation. 2012;126:1023-30.

20. Shi WY, Tatoulis J, Newcomb AE, Rosalion A, Fuller JA, Buxton BF. Is a third arterial conduit necessary? Comparison of the radial artery and saphenous vein in patients receiving bilateral internal thoracic arteries for triple vessel coronary disease. Eur J Cardiothorac Surg. 2016;50:53-60.

21. Glineur D, D’hoore W, Price J, Dorméus S, de Kerchove L, Dion R, et al. Survival benefit of multiple arterial grafting in a 25 -year single-institutional experience: the importance of the third arterial graft. Eur J Cardiothorac Surg. 2012;42: 284-90; discussion 290-1.

22. Buxton BF, Shi WY, Tatoulis J, Fuller JA, Rosalion A, Hayward PA. Total arterial revascularization with internal thoracic and radial artery grafts in triple-vessel coronary artery disease is associated with improved survival. J Thorac Cardiovasc Surg. 2014;148:1238-43; discussion 1243-4.

23. Mohammadi S, Dagenais F, Doyle D, Mathieu P, Baillot R, Charbonneau E, et al. Age cut-off for the loss of benefit from bilateral internal thoracic artery grafting. Eur J Cardiothorac Surg. 2008;33:977-82.

24. Benedetto U, Codispoti M. Age cutoff for the loss of survival benefit from use of radial artery in coronary artery bypass grafting. J Thorac Cardiovasc Surg. 2013; 146:1078-84; discussion 1084-5.

Key Words: coronary, bypass, arterial conduits, right circulation 
TABLE E1. Territory and distribution of grafts to right coronary circulation

\begin{tabular}{|c|c|c|c|}
\hline & $\frac{\text { Venous }(n=274)}{\text { Mean } \pm \text { SD }}$ & $\frac{\text { Arterial }(n=324)}{\text { Mean } \pm \text { SD }}$ & $P$ value \\
\hline Total conduits & $3.99 \pm 0.83$ & $3.44 \pm 0.61$ & $<.001$ \\
\hline n $(\%)$ & & n $(\%)$ & \\
\hline \multicolumn{4}{|l|}{ RCA } \\
\hline LIMA & $0(0.0)$ & $1(0.31)$ & $<.001$ \\
\hline RIMA & $0(0.0)$ & $10(3.09)$ & \\
\hline Radial & $0(0.0)$ & $29(8.95)$ & \\
\hline SVG & $10(3.6)$ & $0(0.00)$ & \\
\hline \multicolumn{4}{|l|}{ RCA-LV } \\
\hline LIMA & $0(0.0)$ & $0(0.00)$ & $<.001$ \\
\hline RIMA & $0(0.0)$ & $6(1.85)$ & \\
\hline Radial & $0(0.0)$ & $51(15.74)$ & \\
\hline SVG & $26(9.5)$ & $0(0.00)$ & \\
\hline \multicolumn{4}{|l|}{ RCA-PDA } \\
\hline LIMA & $0(0.0)$ & $0(0.00)$ & $<.001$ \\
\hline RIMA & $0(0.0)$ & $11(3.40)$ & \\
\hline Radial & $0(0.0)$ & 219 (67.59) & \\
\hline SVG & $274(100.0)$ & $4(1.23)$ & \\
\hline
\end{tabular}

$S D$, Standard deviation; $R C A$, right coronary artery; LIMA, left internal mammary artery; RIMA, right internal mammary artery; $S V G$, saphenous vein graft; $R C A-L V$, right coronary artery to the left ventricle; $R C A-P D A$, right coronary artery posterior descending.
TABLE E2. Territory and distribution of grafts to left coronary circulation

\begin{tabular}{|c|c|c|c|}
\hline & $\frac{\frac{\text { Venous }(n=274)}{\text { Mean } \pm \text { SD }}}{n(\%)}$ & $\frac{\frac{\text { Arterial }(n=324)}{\text { Mean } \pm \text { SD }}}{n(\%)}$ & $P$ value \\
\hline \multicolumn{4}{|l|}{ LAD } \\
\hline LIMA & $261(95.3)$ & $316(97.53)$ & $<.001$ \\
\hline RIMA & $12(4.4)$ & $8(2.47)$ & \\
\hline Radial & $1(0.4)$ & $0(0.00)$ & \\
\hline SVG & $0(0.0)$ & $0(0.00)$ & \\
\hline \multicolumn{4}{|l|}{ OM1 } \\
\hline LIMA & $11(4.0)$ & $6(1.85)$ & $<.001$ \\
\hline RIMA & $34(12.4)$ & 45 (13.89) & \\
\hline Radial & $174(63.5)$ & $227(70.06)$ & \\
\hline SVG & $5(1.8)$ & $2(0.62)$ & \\
\hline \multicolumn{4}{|l|}{ OM2 } \\
\hline LIMA & $1(0.4)$ & $2(0.62)$ & $<.001$ \\
\hline RIMA & $18(6.6)$ & $10(3.09)$ & \\
\hline Radial & $67(24.5)$ & 55 (16.98) & \\
\hline SVG & $6(2.2)$ & $4(1.23)$ & \\
\hline \multicolumn{4}{|l|}{ LCx } \\
\hline LIMA & $1(0.4)$ & $1(0.31)$ & $<.001$ \\
\hline RIMA & $2(0.7)$ & $3(0.93)$ & \\
\hline Radial & $8(2.9)$ & $3(0.93)$ & \\
\hline SVG & $14(5.1)$ & $1(0.31)$ & \\
\hline
\end{tabular}

$S D$, Standard deviation; $L A D$, left coronary artery; LIMA, left internal mammary artery; RIMA, right internal mammary artery; $S V G$, saphenous vein graft; $O M$, obtuse marginal; $L C x$, left circumflex. 
TABLE E3. Survival in unmatched and propensity-matched cohorts

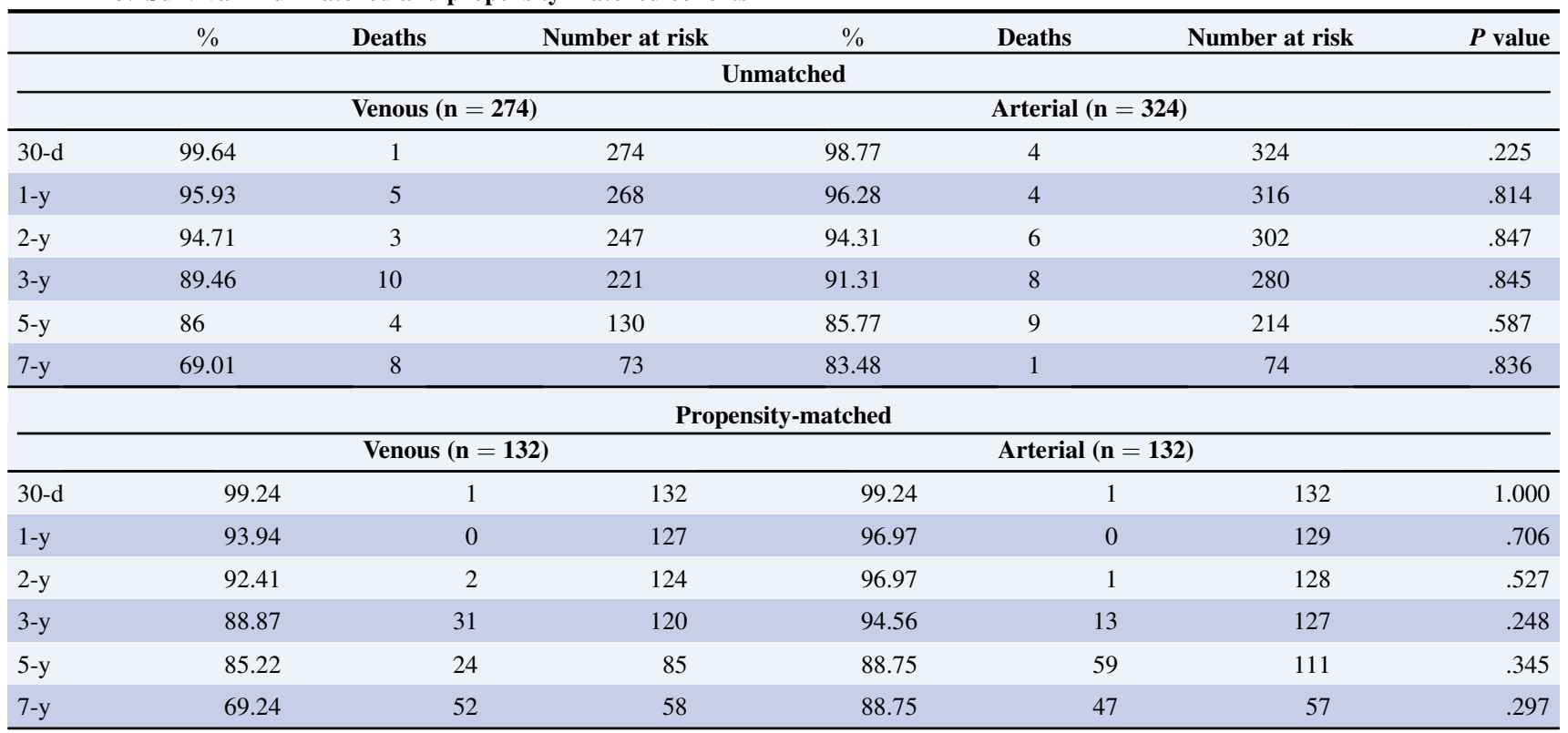

